\title{
MITIGASI RISIKO BERBASIS MARKETING DI LINGKUNGAN PANTI ASUHAN RIYADLUL JANNAH KOTA SEMARANG
}

\author{
Amron $^{1}$, Diana Aqmala ${ }^{2}$, Febrianur Ibnu Fitroh Sukono Putra ${ }^{3}$, Almira Santi Samasta ${ }^{4}$, Kusni \\ Ingsih $^{5}$ \\ 1,2,3,4,5 Fakultas Ekonomi dan Bisnis/Manajemen, Universitas Dian Nuswantoro \\ E-mail: 19amron@dsn.dinus.ac.id, ${ }^{2}$ diana.aqmala@gmail.com, ${ }^{3}$ fbr10@dsn.dinus.ac.id, \\ 4almirasanti@dsn.dinus.ac.id, ${ }^{5}$ Kusni.Ingsih@dsn.dinus.ac.id
}

\begin{abstract}
Abstrak
Risiko dapat terjadi setiap saat, demikian juga risiko yang selalu dihadapi oleh pengelola Panti Asuhan Riyadlul Jannah dirasakan sedemikian komplek. Risiko sehari-hari atau bersifat rutin yang dihadapinya adalah; ketersediaan sembako untuk kebutuhan makan anak asuh, ketersediaan alat cuci, alat mandi, kebutuhan bahan belajar mengajar dan sejenisnya. Selain itu risiko yang bersifat risiko murni adalah; pantai asuhan bocor, kebanjiran, kejatuhan pohon roboh, terbakar dan sejenisnya. Selanjutnya adalah risiko untuk survive yaitu kelangsungan dari penyelenggaraan usaha sosial pantai asuhan, keberlangsungan anak asuh setelah terjun ke masyarakat, serta kemampuan untuk melihat setiap kesempatan bisnis dan pemasaran untuk survive. Metode yang dipergunakan adalah metode mitigasi risiko menggunakan konsep marketing dengan tahapan; identifikasi risiko, tabulasi risiko, prioritas risiko, dan unsur alternatif strategi yang akan dilaksanakan agar Panti Asuhan Riyadlul Jannah tetap survive dan bertahan serta diterima oleh masyarakat luas. Untuk memaksimalkan hasil pengabdian masyarakat maka sarana yang dipergunakan yaitu mitigasi risiko berbasis marketing menggunakan alat bantu berupa web. Mitigasiresiko.com, yang diakses peserta pelatihan untuk mendapatkan pengalaman dalam melakukan mitigasi risiko dengan memanfaatkan unsur-unsur yang ada pada Panti Asuhan Riyadlul Jannah. Tulisan ini mengevaluasi efektifitas dan daya manfaat dari alat bantu web. Mitigasiresiko.com. dalam menunjang pelaksanaan pengabdian masyarakat di Panti Asuhan Riyadlul Jannah.
\end{abstract}

Kata kunci: Mitigasi risiko, identifikasi, tabulasi, marketing

\begin{abstract}
Risks can occur at any time, likewise the risks that are always faced by the managers of the Riyadlul Jannah Orphanage are felt to be complex. The daily or routine risks it faces are; availability of basic foodstuffs for foster children's food needs, availability of washing tools, toiletries, teaching and learning materials needs and the like. Besides that, the risks that are pure risks are; the orphanage beach is leaking, flooded, falling trees, burning. Next is the risk to survive, namely the continuity of the organization of the orphanage beach social business, the sustainability of foster children after entering the community, and the ability to see every business and marketing opportunity to survive. The method used is a risk mitigation method using a marketing concept with stages; risk identification, risk tabulation, risk priority, and elements of alternative strategies that will be implemented so that the Riyadlul Jannah Orphanage will survive and survive and be accepted by the wider community. To maximize the results of community service, the means used, namely marketing-based risk mitigation using tools in the form of the web. Mitigasiresiko.com, which is accessed by training participants to gain experience in mitigating risks by utilizing elements at the Riyadlul Jannah Orphanage. This paper evaluates the effectiveness and usefulness of web tools.
\end{abstract}


Mitigasiresiko.com. in supporting the implementation of community service at the Riyadlul Jannah Orphanage.

Keywords: risk mitigation, identification, tabulation, marketing

\section{PENDAHULUAN}

Kendala yang dihadapi oleh Panti Asuhan Riyaadlul Jannah adalah keterbatasan informasi yang menjelaskan cara mengatasi tentang risiko yang selalu dihadapi oleh pihak Pantai Asuhan. Berbagai risiko seperti risiko sehari-hari atau bersifat rutin yang dihadapi adalah; ketersediaan sembako untuk kebutuhan makan anak asuh, ketersediaan alat cuci, alat mandi, kebutuhan bahan belajar mengajar dan sejenisnya. Selain itu ada risiko yang bersifat risiko murni [1][2] adalah; pantai asuhan bocor, kebanjiran, kejatuhan pohon roboh, terbakar dan sejenisnya[1]. Selanjutnya adalah risiko untuk survive yaitu kelangsungan dari penyelenggaraan usaha sosial pantai asuhan, keberlangsungan anak asuh setelah terjun ke masyarakat, kemampuan bisnis dan berusaha secara mandiri dari segi ekonomi. Untuk menghadapi berbagai risiko tersebut pengelola pantai asuhan harus berhubungan dengan berbagai pihak terutama pihak eksternal untuk menegosiasikan kepentingan-kepentingan sebagai jalan keluar menghadapi risiko[3][4]. Sebagai contoh untuk risiko kekurangan biaya sekolah untuk para anak asuh, maka pihak panti asuhan harus mampu melakukan identifikasi risiko [5][6] sekaligus menegosiasikan risiko tersebut kepada pihak eksternal seperti para donatur agar risiko kekurangan biaya sekolah dapat teratasi. Setiap risiko yang ditangani dengan baik, diolah secara internal dengan profesional dan kemudian dikomunikasikan dengan pihak luar dengan tepat akan menghasilkan solusi yang baik [7][8][9]. Solusi tersebut akan berkesinambungan apabila dikelola dengan identifikasi, profile, tindakkan pencegahan soluasi yang tepat atas risiko tersebut. Untuk menegosisasikan risiko dengan pihak luar maka metode pengabdian yang dipergunakan menggunakan konsep mitigasi risiko berbasis marketing, dengan menggunakan alat bantu web yaitu mitigasiresiko.com. [10][11][12].

Walaupun sudah banyak penelitian dan program pengabdian masyarakat yang telah dilakukan namun tulisan ini berbeda dengan yang lain karena menggunakan konsep mitigasi risiko berbasis marketing dengan menggunakan alat bantu berupa web [9][13][14][15]. Selain itu pengabdian masyarakat ini memiliki perbedaan dengan program lainnya karena mau menguji efektifitas penggunaan web dilihat dari sudut pandang para peserta program pengabdian masyarakat.

Tujuan dari tulisan ini adalah agar menjadi masukkan bagi para pengabdi lainnya yang menjalankan program pengabdian dalam bidang manajemen pemasaran maupun manajemen risiko, dengan melibatkan alat bantu berupa web.

\section{METODE}

Metode yang dipergunakan dalam pengujian terhadap hasil pengabdian masyarakat dengan menggunakan alat web adalah menggunakan uji usability atau dikenal juga dengan nama USE. Metode ini dipergunakan dengan untuk mengetahui persepsi para peserta dari pengabdian masyarakat yang dilakukan di Panti Asuhan Riyaadlul Jannah. USE biasa dipakai untuk pengujian karena mengacu kepada sistem ISO yang sudah terstandarisasi. Pada pengujian melalui USE dipergunakan variabel utama meliputi; tingkat penggunaan, tingkat kemudahan. Pengujian menggunakan 25 orang sebagai responden yang semuanya adalah peserta pelatihan pengabdian masyarakat yang telah mengoperasikan laman web mitigasiresiko.com. Sedangkan instrumen masing-masing variabel terdiri dari 8 dan 4 item pertanyaan. Selanjutnya item pertanyaan akan diisi oleh semua responden yang telah merasakan manfaat dari alat bantu berupa web dalam pelaksanaan pengabdian masyarakat, selanjutnya data yang terkumpul dilakukan tabulasi sekaligus dilakukan analisis deskriptif untuk kemudian disimpulan secara partial dan komprehensif untuk mengetahui perspesi dari semua peserta pelatihan pengabdian masyarakat. Sedangkan skoring dilakukan dengan pemberian angka satu untuk skor terendah 
dan angka 5 untuk skor tertinggi.

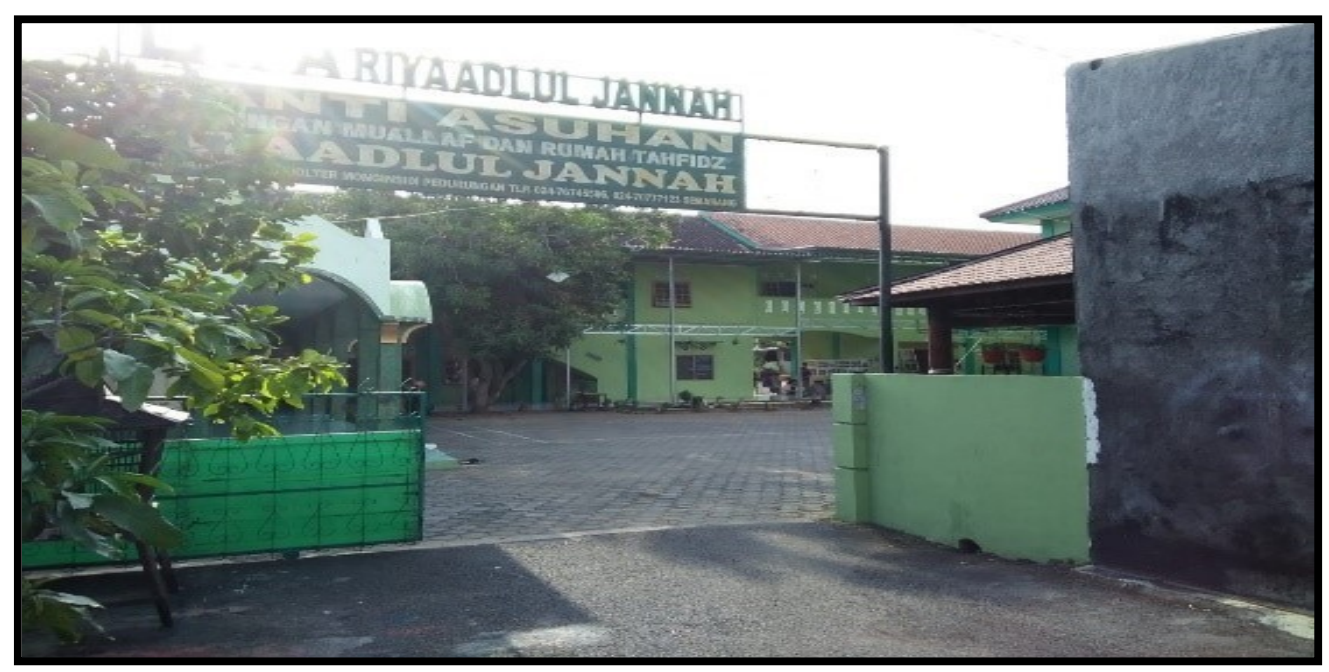

Gambar 1 Lokasi depan Pantai Asuhan Riyadlul Jannah

\section{HASIL DAN PEMBAHASAN}

Berdasarkan hasil kuesioner yang disebar kepada para responden peserta pelatihan pengabdian masyarakat mitigasi risko berbasis marketing, diperoleh informasi bahwa para peserta mendapatkan manfaat dan perkembangan yang signifikan khususnya dalam penanganan risiko dan penanggulangan risiko. Secara garis besar manfaat yang diperoleh para peserta adalah;

1) Peningkatan kualitas penanganan risiko

Semua peserta pelatihan merasakan manfaat yang sangat besar dalam meningkatkan pengetahuan dalam penanganan risiko, dimana selama ini risiko-risiko yang berada disekeliling Panti Asuhan Riyadlul Jannah, sebelumnya terlihat sulit dan tidak mudah dipecahkan ternyata dengan metode mitigasi risiko dapat terselesaikan dengan baik. Kemudahan penyelesaian masalah risiko di dukung oleh penggunaan alat aplikasi berupa web mitigasiresiko.com.

\section{2) Peningatan penerapan IPTEK}

Alat aplikasi yang dipergunakan dalam pelatihan pengabdian masyarakat di Panti Asuhan Riyadlul Jannah, dirasakan oleh para peserta mudah dipahami dan diaplikasikan. Semua peserta menyampaikan testimoninya bahwa walaupun aplikasi adalah baru bagi mereka namun para peserta merasakan kemudahan dan manfaat yang sangat besar dalam membantu proses mitigasi risiko berbasis marketing.

3) Perbaikan tata nilai dalam penanganan tata kelola mitigasi risiko

Semua peserta pelatihan menyampaikan bahwa proses identifikasi risko, tabulasi risiko, dan eksposur risiko yang diberikan selama pelatihan diikuti dengan praktek menggunakan alat bantu aplikasi berbasis web, mampu memberikan kontribusi yang positif dalam memandang dan melaksanakan tata nilai mitigasi risio dengan paradigma baru. Sebelumnya para peserta merasa bahwa setiap risiko yang muncul akan menjadi malapetaka dan menyebabkan kerugian yang tidak terduga. Ternyata setelah menerima pelatihan dan praktik menggunakan aplikasi berbasis web kenyataannya hal tersebut tidak sepenuhnya benar karena risiko dapat dikelola. 


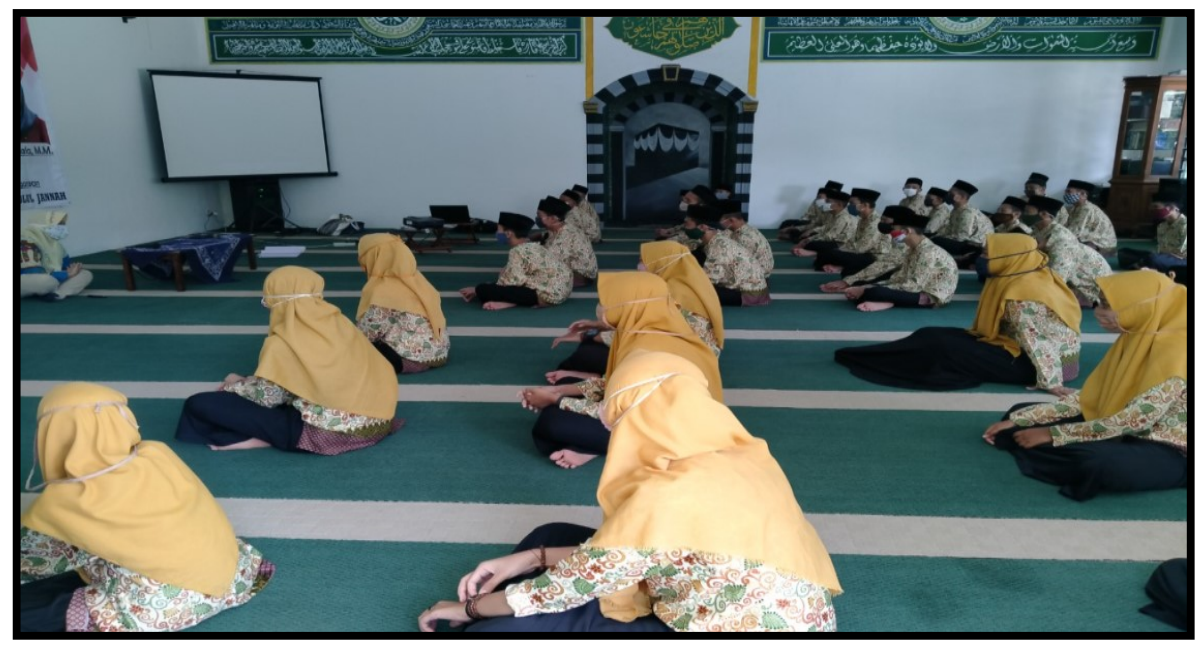

Gambar 2 Peserta pelatihan pengabdian masyarakat

Berdasarkan kuesioner yang disebarkan kepada 25 peserta pelatihan diperoleh data bahwa sebanyak 15 responden adalah perempuan dan sisanya adalah laki-laki. Sedangkan tingkat pendidikan adalah SMA rata-rata kelas1, 2 dan 3. Berikut adalah hasil tabulasi data dan analisis deskriptif dari data primer yang diperoleh dari para responden.

\subsection{Kegunaan (nilai guna) aplikasi berbasis web}

Kegunaan atau nilai guna yang dirasakan oleh para peserta pelatihan pengabdian masyarakat diwakili dengan menjawab pertanyaan/kuesioner yang terdiri dari 8 item pertanyaan. Pertanyaan pertama menggambarkan persepsi dari responden atas dasar kegunaan/nilai guna aplikasi berbasis web dilihat dari segi efektifitas. Pertanyaan ke dua melihat alat bantu aplikasi berbasis web dilihat dari segi produktifitas, sedangkan pertanyaan ke tiga melihat dari sisi perspesi penggunaan alat aplikasi dari segi nilai guna secara individual. Pertanyaan ke empat melihat alat aplikasi berbasis web dilihat dari kemampuan mengontrol pekerjaan secara efektif, selanjutnya pertanyaan ke lima melihat alat aplikasi dari sisi memudahkan tujuan para pengguna dalam melaksanakan pekerjaan mitigasi risiko. Pertanyaan nomor enam mengangkat peran alat aplikasi dalam membantu peserta pelatihan pengabdian dalam menghemat waktu, serta pertanyaan nomor tujuh melihat alat aplikasi berbasis web mitigasi risiko dari segi kemampuan membantu peserta pelatihan pengabdian masyarakat dari segi pemulihan kesalahan yang tidak disegaja selama mitigasi risiko. Pertanyaan terakhir adalah untuk memastikan persepsi para peserta pelatihan bahwa manfaat dan kegunaan alat aplikasi berbasis web betul-betul mampu membantu peserta secara efektif dalam melakukan proses mitigasi risiko.

Tabel. 1 Kegunaan aplikasi berbasis web

\begin{tabular}{|l|l|l|l|l|l|l|l|l|l|l|l|}
\hline \multicolumn{1}{|c|}{ Pertanyaan } & \multicolumn{2}{|c|}{ STS } & \multicolumn{2}{c|}{ TS } & \multicolumn{2}{c|}{ N } & \multicolumn{2}{c|}{ SS } \\
\cline { 2 - 13 } & F & S & F & S & F & S & F & S & F & S \\
\hline $\begin{array}{l}\text { 1.Alat aplikasi berbasis web menjadikan mitigasi } \\
\text { risiko bekerja lebih efektif }\end{array}$ & 0 & 0 & 0 & 0 & 4 & 12 & 11 & 44 & 10 & 50 \\
\hline $\begin{array}{l}\text { 2.Alat aplikasi berbasis web menjadikan } \\
\text { mitigasi risiko bekerja lebih produktif }\end{array}$ & 0 & 0 & 0 & 0 & 5 & 15 & 10 & 40 & 10 & 50 \\
\hline $\begin{array}{l}\text { 3.Alat aplikasi berbasis web menjadikan } \\
\text { sangat berguna untuk mitigasi risiko }\end{array}$ & 0 & 0 & 0 & 0 & 3 & 9 & 11 & 44 & 11 & 55 \\
\hline $\begin{array}{l}\text { 4.Alat aplikasi berbasis web menjadikan } \\
\text { sangat berguna untuk mengontrol risiko }\end{array}$ & 0 & 0 & 0 & 0 & 4 & 12 & 12 & 48 & 9 & 45 \\
\hline $\begin{array}{l}\text { 5.Alat aplikasi berbasis web mempermudah } \\
\text { mencapai tujuan mitigasi risiko }\end{array}$ & 0 & 0 & 0 & 0 & 4 & 12 & 13 & 52 & 8 & 40 \\
\hline $\begin{array}{l}\text { 6.Alat aplikasi berbasis web menjadikan } \\
\text { sangat menghemat waktu }\end{array}$ & 0 & 0 & 0 & 0 & 5 & 15 & 14 & 56 & 6 & 30 \\
\hline
\end{tabular}




\begin{tabular}{|l|l|l|l|l|l|l|l|l|l|l|}
\hline $\begin{array}{l}\text { 7.Alat aplikasi berbasis web sesuai dengan } \\
\text { keinginan pengguna }\end{array}$ & 0 & 0 & 0 & 0 & 5 & 15 & 14 & 56 & 6 & 30 \\
\hline $\begin{array}{l}\text { 8.Alat aplikasi berbasis web sesuai dengan } \\
\text { harapan }\end{array}$ & 0 & 0 & 0 & 0 & 5 & 15 & 13 & 52 & 7 & 35 \\
\hline
\end{tabular}

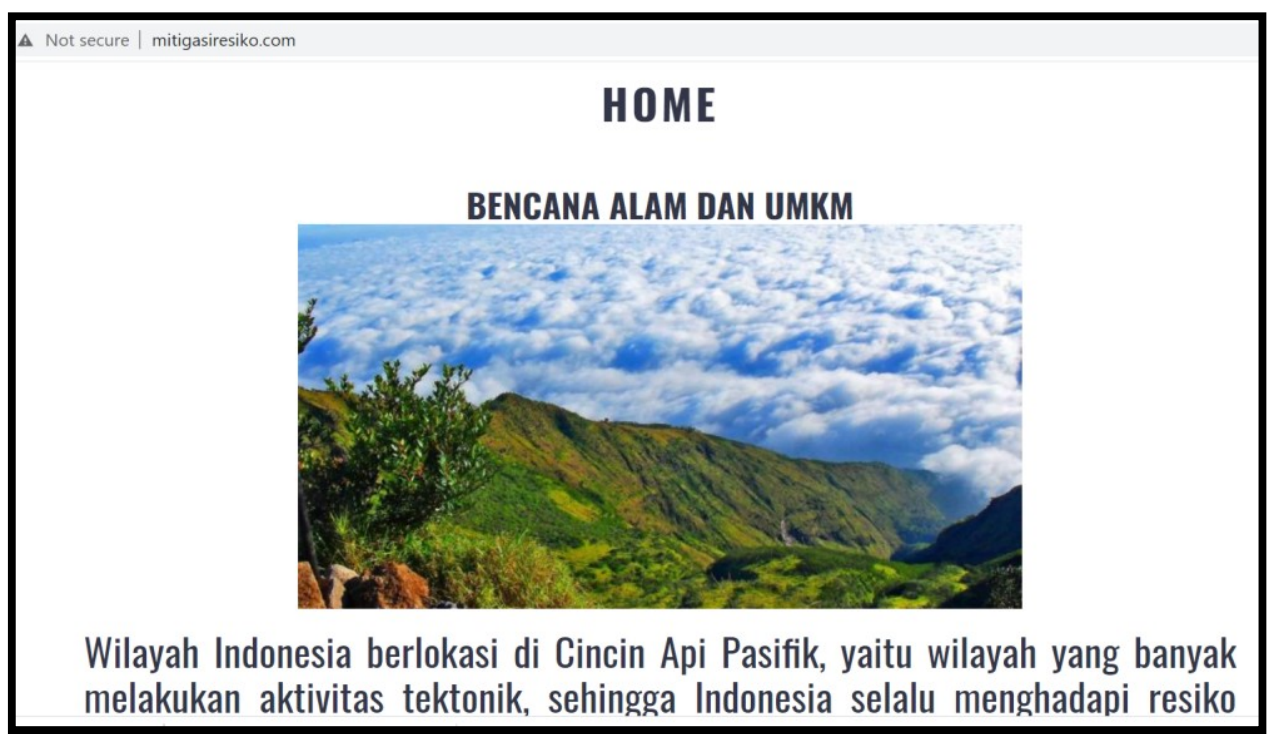

Gambar 3 Tampilan web mitigasiresiko.com

Berdasarkan hasil tabulasi responden terhadap tanggapan nilai guna dari alat aplikasi berbasis web mitigasiresiko.com diperoleh informasi bahwa frekwensi responden yang memberikan penilaian maksimal sebanyak 10 orang, sehingga total score akumulasi adalah 12 ditambah 44 dan ditambah skor maksimal 50 sehingga total score adalah 106, apabila di bagi dengan jumlah responden sebanyak 25 orang maka indeksnya adalah 4,24. Selanjutnya untuk tanggapan pada item alat aplikasi berbasis web menjadikan mitigasi risiko bekerja lebih produktif diperoleh total sekor dari penjumlahan sub score 15 ditambah dengan 40 dan ditambah dengan skor maksimal 50 hasilnya adalah 105, kemudian dibagi dengan jumlah responden maka menghasilkan indeks rata-rata sebesar 4,2. Kemudian untuk alat aplikasi berbasis web menjadikan sangat berguna untuk mitigasi risiko, memiliki total skor sebanyak 108 merupakan total dari sub skor 9 ditambah 44 dan ditambah skore maksimal sebesar 108, sehingga apabila dibagi dengan jumlah responden sebanyak 25 orang maka hasilnya adalah 4,32. Untuk item pertanyaan Alat aplikasi berbasis web menjadikan sangat berguna untuk mengontrol risiko memperoleh total skor sebesar 105 yaitu berasal dari sub skore 12 ditambah dengan 48 dan sub skor maksimal sebesar 45, apabila total skor dibagi dengan jumlah responden maka menghasilkan indeks sebesar 4,2. Pada poin pertanyaan alat aplikasi berbasis web mempermudah mencapai tujuan mitigasi risiko, ternyata responden memberikan sub skor masing-masing 12,52 , dan skor maksimal sebesar 40, sehingga totalnya adalah 104, sedangkan indeks mencapai 4,16. Kemudian untuk pertanyaan alat aplikasi berbasis web menjadikan sangat menghemat waktu, memiliki total skor sebesar 4,04 yaitu berasal dari sub skor 15, dan 56, ditambah dengan skore maksimal sebesar 30, apabila dibagi dengan total responden maka indeksnya mencapai nilai 4,04. Pada pertanyaan ke 7 yaitu alat aplikasi berbasis web sesuai dengan keinginan pengguna memiliki skor dari masing-masing sub item sebesar 15 ditambah dengan 56 dan ditambah dengan skor maksimal sebesar 30, sehingga total adalah 101, kemudian diperoleh angka indeks sebesar 4,04 setelah total skor dibagi dengan jumlah responden. Selanjutnya untuk item pertanyaan terakhir yaitu alat aplikasi berbasis web sesuai dengan harapan memperoleh total skor sebesar 102 yang berasal dari penjumlah sub skor masingmasing sebesar15, 52, dan 35, dengan indeks sebesar 4,08.

Berdasarkan hasil pernyataan dari reponden tersebut di atas dapat disimpulkan bahwa 
untuk tingkat nilai kegunaan aplikasi berbasis web yang dipergunakan sebagai media bantu pada pengabdian masyarakat ternyata dari tabulasi data diperoleh informasi; 1) item alat aplikasi berbasis web menjadikan mitigasi risiko bekerja lebih efektif, memiliki nilai indeks terbesar dibandingkan dengan item pertanyaan lainnya yang diajukan kepada para responden. Hal ini menunjukkan bahwa bagi para responden yang terpenting dalam penggunaan alat bantu aplikasi berbasis web untuk mitigasi risiko adalah seberapa efektif dapat dipergunakan untuk menghasilkan mitigasi risiko yang akurat. Ini menjadi perhatian bagi para pelaku mitigasi risiko agar dalam menyediakan alat bantu berupa web harus mampu menjadikan setiap menu pada web menjadi efektif dan mudah dipergunakan oleh para user, sehingga menghasilkan data-data yang update untuk mitigasi risiko. 2) Item kedua yang menjadi perhatian dan dianggap penting untuk mitigasi risiko adalah alat aplikasi berbasis web menjadikan sangat berguna untuk mitigasi risiko, artinya responden berpendapat bahwa nilai kegunaan dari aplikasi berbasis web yang dipergunakan pada pelatihan sangat diperlukan khususnya untuk mendukung daya guna agar mitigasi risiko yang dijalankan menjadi bernilai dan memiliki keakuratan yang baik.

\subsection{Tingkat kemudahan untuk dipelajari}

Aplikasi berbasis web untuk keperluan mitigasi risiko dibuat sedemikian rupa dengan profile dan menu yang mudah dipahami oleh pengguna. Untuk membuktikan bahwa aplikasi yang dipakai untuk alat pembantu pada pengabdian masyarakat sudah sesuai dengan karakteristik pengguna, maka para peserta pelatihan diminta untuk menjawab 4 pertanyaan tentang tingkat kemudahan alat aplikasi dari sudut persespi peserta. Pertanyaan pertama adalah alat aplikasi berbasis web memiliki prosedur yang mudah dipelajari, artinya dari sudut perspesi para pengguna aplikasi apakah fitur dan menu yang ditawarkan oleh aplikasi mudah dipelajari terkait sebagai alat bantu dalam melakukan mitigasi risiko. Pertanyaan kedua adalah alat aplikasi berbasis web memiliki cara penggunaan yang mudah diingat, dimaksudkan agar cara penggunaan yang efisien dan efektif benar-benar teruji setelah ditanyakan langsung kepada para pengguna aplikasi. Jawaban dari para responden atas testimoni paska penggunaan alat akan memetakan apakah aplikasi tersebut familier dan mudah diingat dalam pengoperasiannya oleh para pengguna. Selanjutnya pertanyaan ke tiga adalah alat aplikasi berbasis web memiliki sistim operasional yang mudah dipahami, artinya sistem operasi aplikasi yang dipergunakan untuk proses mitigasi risiko mudah dipahami oleh para pengguna. Pertanyaan terakhir terkait dengan aplikasi adalah alat aplikasi berbasis web menjadikan para pengguna cepat terampil, maksudnya dengan menggunakan aplikasi para peserta menyelesaikan proses mitigasi risiko dengan lebih cepat dan trampil serta dengan hasil yang sangat efektif.

Tabel. 2 Aplikasi berbasis web mudah dipelajari

\begin{tabular}{|c|c|c|c|c|c|c|c|c|c|c|}
\hline \multirow[t]{2}{*}{ Pertanyaan } & \multicolumn{2}{|c|}{ STS } & \multicolumn{2}{|c|}{$\mathrm{TS}$} & \multicolumn{2}{|c|}{$\mathrm{N}$} & \multicolumn{2}{|c|}{$\mathrm{S}$} & \multicolumn{2}{|c|}{ S S } \\
\hline & $\mathrm{F}$ & $\mathrm{S}$ & $\mathrm{F}$ & $\mathrm{S}$ & $\mathrm{F}$ & $\mathrm{S}$ & $F$ & $\mathrm{~S}$ & $\mathrm{~F}$ & $\mathrm{~S}$ \\
\hline $\begin{array}{l}\text { 1.Alat aplikasi berbasis web memiliki prosedur } \\
\text { yang mudah dipelajari }\end{array}$ & 0 & 0 & 0 & 0 & 5 & 15 & 11 & 44 & 9 & 45 \\
\hline $\begin{array}{l}\text { 2.Alat aplikasi berbasis web memiliki cara } \\
\text { penggunaan yang mudah diingat }\end{array}$ & 0 & 0 & 0 & 0 & 6 & 18 & 10 & 40 & 9 & 45 \\
\hline $\begin{array}{l}\text { 3.Alat aplikasi berbasis web memiliki sistim } \\
\text { operasional yang mudah dipahami }\end{array}$ & 0 & 0 & 0 & 0 & 4 & 12 & 11 & 44 & 10 & 50 \\
\hline $\begin{array}{l}\text { 4.Alat aplikasi berbasis web menjadikan } \\
\text { para pengguna cepat terampil }\end{array}$ & 0 & 0 & 0 & 0 & 4 & 12 & 11 & 44 & 10 & 50 \\
\hline
\end{tabular}

Berdasarkan hasil pendapat dari responden atas pertanyaan pertama tentang aplikasi mudah dipelajari diperoleh skor dari penjumlahan skor awal 15 ditambah dengan 44, dan ditambah dengan skor maksimal 45 sehingga diperoleh total skor sebesar 104, indeksnya diperoleh angka sebesar 4,16 yaitu total skor setelah dibagi dengan total responden. Selanjutnya atas pertanyaan kemudahan alat aplikasi mudah diingat cara pengopersionalannya oleh para peserta, diperoleh skor total 103 yaitu penjumlahan dari sub skor 18 ditambah dengan 40 dan 45 , sedangkan indeksnya mencapai nilai 4,12. Kemudian atas pertanyaan yang terkait dengan sistem operasional alat aplikasi berbasis web yang mudah dipahami dalam proses mitigasi risiko diperoleh angka skor dari penjumlahan 12 ditambah 44, kemudian ditambahkan skor maksimal 
50, sedangkan indeksnya mencapai 4,24 yaitu berasal dari total skor dibagi dengan jumlah total skor.Pertannyaa selanjutnya yang membahas tentang alat aplikasi berbasis web mampu menjadikan para pengguna menjadi cepat terampil dalam proses mitigasi risiko, mendapatkan skor total sebesar 106, merupakan jumlah dari skor awal sebesar 12 ditambah dengan 44, selanjutnya ditambahkan dengan jumlah skor maksimal sebesar 50, adapun indeksnya adalah total skor sebesar 106 dibagi dengan 25 peserta yang hasilnya adalah 4,24.

Selanjutnya dari uraian pembahasan tersebut di atas dapat di simpulkan bahwa secara parsial persepsi responden yang telah menggunakan alat aplikasi berbasis web ternyata mereka menempatkan pernyataan alat aplikasi mudah dipahami adalah hal yang paling penting yang harus diperhatikan dalam pemilihan alat bantu dalam melakukan mitigasi risiko. Namun secara mengejutkan ternyata item alat aplikasi mampu menjadikan para pengguna menjadi cepat terampil dalam melakukan mitigasi risiko memiliki skor yang sama yaitu sebesar 4,24. Hal ini membuktikan bahwa dari segi alat aplikasi mudah dipelajari, yang paling dianggap penting untuk diperhatikan oleh para peserta pelatihan terkait dengan alat aplikasi adalah kriteria alat aplikasi mudah dipahami serta mampu meningkatkan kinerja para pengguna alat aplikasi karena mudah dipelajari oleh para pengguna. Kemudian pertanyaan item pertama memiliki skor sebesar 4,16 dan diikuti dengan item kedua dengan skor sebesar 4,12. Hal ini memberikan gambaran kepada para penyelenggara pelatihan mitigasi risiko agar menyediakan alat bantu aplikasi berbasis web dengan kriteria mudah dipelajari dan menampilkan menu yang mudah diingat, sehingga mampu memudahkan proses mitigasi risko berbasis marketing secara efektif.

\section{KESIMPULAN DAN SARAN}

Pelatihan mitigasi risiko berbasis marketing yang dilakukan dengan menggunakan alat bantu aplikasi berbasis web telah dilakukan dengan baik bertempat di Panti Asuhan Riyadlul Jannah. Berdasarkan pendapat para responden peserta pelatihan mitigasi risko berbasis marketing yang telah dilakukan dengan menggunakan alat bantu aplikasi risiko berbasis web diperoleh fakta bahwa secara umum para peserta merasakan manfaat dari pelatihan tersebut antara lain kemampuan memahami dan meningkatnya kualitas penanganan risiko, disamping itu juga para peserta merasa adanya perbaikan pada tata nilai khususnya dalam memandang dan mengklasifikasikan risiko menjadi risiko yang mudah dipahami dan dapat dicarikan alternatif solusi penanganannya. Secara khusus dari jawaban para respondent diperoleh fakta bahwa item nilai kegunaan alat adalah hal yang dirasakan paling penting dalam penggunaan alat aplikasi mitigasi risiko berbasis marketing. Sedangkan item kedua terpenting menurut responden adalah alat aplikasi mudah dipahami serta pengguna menjadi cepat terampil menggunakannya.

Mendasarkan kepada hal tersebut di atas maka dapat disarankan kepada para pelaku pelatihan pengabdian masyarakat yang menggunakan alat aplikasi berbasis web terutama yang terkait dengan topik mitigasi risiko berbasis marketing, dapat melakukan langkah-langkah antisipasi dalam memaksimalkan nilai guna dengan menonjol peran alat aplikasi agar mampu menunjang pekerjaan mitigasi risiko secara efisien, cara yang dilakukan misalnya dengan menyederhanakan menu-menu yang harus dikenali oleh para pengguna, selain itu juga dengan memberikan prosedur yang lebih simpel agar tidak menyulitkan para pengguna. Selain itu dari segi alat aplikasi mudah dipahami, dapat disarankan agar menggunakan bahasa dan gambar petunjuk yang mudah dipahami, bisa dengan memberikan kesan mudah dan pengguna merasa cepat mahir tanpa harus dibebani dengan bahasa pemrograman yang terkesan sulit.

\section{UCAPAN TERIMA KASIH}

Sehubungan dengan telah dilaksanakan pengabdian masyarakat ini dengan baik, maka Tim pengabdian masyarakat mengucapakan terima kasih kepada Lembaga Penelitian dan Pengabdian kepada Masyarakat Universitas Dian Nuswantoro, karena dengan pemberian hibah dana penenelitan/pengabdian. Selain itu diucapkan terima kasih kepada Panti Asuhan Riyaadlul Jannah, yang telah bekerjasama dengan baik sehingga pelaksanaan acara pengabdian 
masyarakat dapat berjalan dengan baik.

\section{DAFTAR PUSTAKA}

[1] AAMAI (2018). Materi Ujian Profesi AAMAI Mitigasi Risiko. Asosiasi Ahli Manajemen Asuransi Indonesia. Kantor Komisariat Jawa Tengah di Semarang.

[2] Amron, A. (2018). Electronic and traditional word of mouth as trust antecedents in life insurance buying decision. International Journal of e-Business Research, Vol. 14, No. 4, pp. 91-103.

[3] Amron and Mahmud. (2015). Product quality and premium as the antecedents to customer decision with the impact on the loyalty of export insurance customers in South Sulawesi. European journal of business and management (EJBM), Vol. 7, No.24, pp.73-81.

[4] Asseldonk, M.V., Meulen, H.V.D., Meer, R.V.D., Silvis, H. \& Berkhout, P. (2018). Does subsidized MPCI crowds out traditional market-based hail insurance in the Netherlands? Agricultural Finance Review, 78(2): 262-274.

[5] Bera, M.K. and Danek, P. (2017).The perception of risk in the flood-prone area: a case study from the Czech municipality. Disaster Prevention and Management, 27(1): 2-14.

[6] Chang, C.H., Xu, J. and Song, D.P. (2015). Risk analysis for container shipping: from a logistics perspective, The International Journal of Logistics Management, Vol. 26 Issue: 1, pp.147-171, doi: 10.1108/IJLM-07-2012-0068.

[7] Christodoulides, G., Michaelidou, N. \& Argyriou, E. (2012). Cross-nationaldifferences in e- WOM influence, European Journal of Marketing, Vol. 46 No. 11/12, pp. 1689- 1707.

[8] Enjolras, G. and Kast, R. (2012). Combining participating insurance and financial policies: A new risk management instrument against natural disasters in agriculture, Agricultural Finance Review, Vol. 72 Issue: 1,pp. 156-178, doi: 10.1108/00021461211222231.

[9] Falkner, E.M., and Hiebl, M.R.W. (2015). Risk management in SMEs: a systematic review of available evidence, The Journal of Risk Finance, Vol. 16 Issue: 2, pp.122- 144, doi: 10.1108/JRF-06-2014-0079.

[10] Glauber, J.W. ; Collins, K.J.; and Barry, P.J. (2002). Crop insurance, disaster assistance, and the role of the federal government in providing catastrophic risk protection, Agricultural Finance Review, Vol. 62 Issue: 2,pp. 81-101, doi: 10.1108/00214900280001131.

[11] Keskin, B., Dunning, R. and Watkins, C. (2017). Modelling the impact of earthquake activity on real estate values: a multi-level approach. Journal of European Real Estate Research, 10 (1) : 7390 .

[12] Kumar, Sameer; Himes, Katie J., and Kritzer, Collin P. (2014), Risk Assessment and Operational Approaches to Managing Risk in Global Supply Chains, Journal of Manufacturing Technology Management, Vol. 25 Issue: 6.

[13] Lyu K. and Barre, T.J. (2017). Risk aversion in crop insurance program purchase decisions Evidence from maize production areas in China. China Agricultural Economic Review, 9 (1) : 62 -80 .

[14] Maenpaa, I. and Voutilainen, R. (2012), Insurances for human capital risk management in 
SMEs, VINE, Vol. 42 Issue: 1,pp. 52-66, doi: 10.1108/03055721211207761

[15] Zorrilla, S.O.S. (2015). Assessment of disaster risk management in Mexico, Disaster Prevention and Management, Vol. 24 Issue: 2,pp. 230-248, doi: 10.1108/DPM-11- 2013-0201 